\title{
Increasing Self-Esteem and School Connectedness Through a Multidimensional Mentoring Program
}

\author{
Keith A. King, Rebecca A. Vidourek, Beth Davis, Warren McClellan
}

\begin{abstract}
High levels of selfesteem and positive whool. peer, and family connections represent protective factors again.t youth involvement in risky behavior. This paper reports findings from year one of the Healthy Kids Mentoring Program, a multidisciplinary mentoring program for fourth-grade students in a Midwestern public school. In October 2000. 28 fourth-grade students were admitted into the program, based on findings from a 55 -item survey distributed to all fourth-grads students $(N=283)$ regarding overall selfexteem, school, perr. and family comertednes and inwehement in risky behavior. The program, which ran from January 2000 10 May 200\%, consisted of fout components: 1) relationship building. 2) self-esteem enhancement, 3) goal setting. 4) academic assistance. Prest-Postest datu showed significant improvements at posttest in mentored students' self-esteem le'vels and positive connections to shool, peers, and family. Mentored students also were significantly tess likety to be depressed or involved in bullying and fighting at pestest than at pretest. Compared to nonmentored students, mentored students reported significanty higher school and family tonnectedness scores at postest. Reconmendations for effective mentoring program design are offered. (J Sch Health. 2002:72(7):294-299)
\end{abstract}

$\mathbf{R}_{\mathrm{f}}^{\mathrm{e}}$ esearch indicates high self-esteem serves as a protective factor to youth involvement in risky health behavior." High self-esteem is associated with high academic achievement, involvement in sport and physical activity, and development of effective coping, and peer pressure resistance skills. ${ }^{4.5}$ Conversely, low self-esteem is associated with youth involvement in alcohol, tobacco, and other drug use; depression; suicide; violence; early sexual activity; teenage pregnancy; and poor peer relationships. ${ }^{(t-12}$ In the school environment, high levels of self-esteem increase the likelihood that youth will connect positively to peers, teachers, and the school as a whole, important determinants of academic success.

Similar to self-esteem, a sense of positive school, peer, and family connectedness (feeling that one "fits in" and "belongs") protects youth from engaging in negative health behavior. ${ }^{4,10,13.14}$ Positive social connections decrease risklaking behavior by providing youth with prosocial and empowering opportunities. (4.15 $^{1}$ Youth who feel supported and cared for by parents, teachers, and peers report feeling more efficacious in making healthy, informed decisions and displaying features of resiliency to potential life stressors. ${ }^{\text {it }}$

Students spend a large portion of their time in school, so school-based health education and prevention programs have been implemented to increase youth self-esteem and positive school, peer, and family connections. These programs focus on getting students involved in interactive, student-oriented, decision-making, cooperative learning activities, as well as including aspects of parental involvement, peer counseling, tutoring, and mentoring.

The specific aspect of mentoring involves pairing an adult or youth with a student needing assistance. "The overarching goal of most mentoring programs is to reduce risky behavior while connecting the youth in need to an individual from the school or community. ${ }^{1421}$ The mentor serves as a positive role model while providing emotional and social

Keith A. King, PhD, CHES, Assistant Professor, Health Promotion and Education Program, University of Cincinnati, Ml.0002, $526 \mathrm{TC}$, Cincimmuti, OH 75221-0002; (keith.king(auced(h); Rebecca A. Vidourek, BEd, Restarrh Assistam, Healh Promotion and Education Program. University of Cincimati, ML 0002,526 TC Cincinnati, oll 45221-(0002: Beth Davis, MS, Project Ceordinator. Healthy Kids - It's My Time, Cincimati, OH; and Warren McClellan, MEd, Principal, Loncland Intemediate School, Cincinnati. OH. This article was subnitted Jamury 3. 2002, and revised and aceptral for publication May 28, 2002 support and academic assistance. While mentoring programs can have beneficial effects, unfortunately a substantial percentage of these programs point solely to anecdotal evidence to support their overall effectiveness. Furthermore, preventive interventions often occur in the middle or high school years, despite the fact that early interventions may prove more effective in preventing current and future negative health behavior. ${ }^{21}$ Early interventions are critical to preventing future health problems. Nevertheless, few evaluative studies on elementary school mentoring programs have been published in the professional literature.

This exploratory study was undertaken to determine overall effectiveness of the Healthy Kids Mentoring Program in fostering high levels of self-esteem and positive school, peer, and family connections. Due to the exploratory nature of the study, readers are encouraged to view this paper as an overall program description and process evaluation with preliminary findings. If successful program results were found then future youth engagement in negative health behaviors may be prevented and child health status may be improved.

\section{Program Description}

The Healthy Kids Mentoring Program, designed for fourth-grade students at a Midwestern suburban public school, consisted of four components: 1) relationship building, 2) self-esteem enhancement, 3) goal setting, and 4) academic assistance (tutoring). Mentors met with students twice each week for $1 \frac{1}{2}$ hours each session on school grounds. During each meeting, mentors devoted time to each program component.

Relationship Building. To develop a positive relationship with a student, mentors were instructed to use dialogue journals and continuous meeting icebreakers. Each week. mentors read one question (provided by the program coordinator and evaluator) in a dialogue journal, replied by writing their answers and thoughts in the journal, then passed the journal on to the student they were mentoring at the next mentoring session. Examples of dialogue questions included, "What are you most proud of having accomplished?" "What is the bravest thing that you ever did?" "Who are your heroes and why?" "What is the hardest 
thing about growing up?" Students read the mentors' responses, answered the question themselves, answered any questions the mentor posed for them, then posed a question for the mentor to answer. Mentors and students used the journal to communicate and learn more about each other.

Mentors also received descriptions of several small icebreakers to use with the students in the program. At the beginning of each mentoring session, mentors conducted a brief icebreaker to foster positive connections between mentor and student. Examples included "My unique characteristics," "Discussion of your three wishes," and "Important things about myself."

Self-Esteem Enhancement. Mentors received a guidebook of self-esteem enhancement activities to use with the students they were mentoring. The activities were developed based on the four conditions of self-esteem: sense of connectedness, sense of power, sense of uniqueness, and sense of positive role models." Mentors were encouraged to choose activities they believed would prove most suitable and effective for the child, while ensuring that at least one activity was chosen from each of the four self-esteem conditions. Examples included "Developing a Me Poster," "Writing a Name Poem," and "Constructing a Happiness is Booklet."

Goal Setting. During the first mentoring session of each week, students worked with mentors to develop a goal they would try to accomplish that week. Examples of goals included completing all homework as assigned, answering a question in class, complimenting a peer, thanking a teacher or parent for their help, and developing a list of characteristics of a positive friend. Mentors assisted students in developing their weekly goals by ensuring the goals were moasurable, realistic, and obtainable. Each week, a goal agreement form was completed by students and their mentors. The form included the date the goal was developed, target completion date, actual goal, why the student wished to complete this goal, and signatures of the student, mentor, and parent/guardian.

Academic Assistance. Students in the program often had difficulty in the specific school subject of reading. Therefore, mentors were encouraged to spend 15 to 30 minutes each session helping students complete assigned readings and study assigned vocabulary/spelling words. To ensure consistency with academic assistance, mentors received training sessions as well as guides on strategies to increase reading and academic skills. 23.24 The program coordinator personally contacted mentors bimonthly to address goals, strategies, and potential difficulties, and to maintain consistency and integrity of the program.

\section{Mentor Recruitment and Training}

In November 1999, 32 mentors were recruited from the community where the school was located. Mentors ranged from high school students to senior citizens. In December 1999. mentors received initial training regarding the program specifics by the program coordinator, school principal, and project evaluator. In this initial training session, the four program components were delineated clearly, examples were provided, mentor behavioral expectations were set, legal issues were discussed, and questions were taken. Mentors received a program guidebook that provided them with examples of activities to engage in with students to enhance self-esteem and foster a positive relationship. Mentors also were encouraged to use a dialogue journal with students to help develop the mentoring relationship.

In December 1999, mentors received a second program training session. An expert in literacy education from a nearby university provided effective strategies mentors could use to help students become more interested in reading, as well as to improve their reading skills. A guidebook of practical reading enhancement strategies was provided to all mentors and to the school library. ${ }^{2 s}$

\section{Program Coordinator Responsibilities}

The program coordinator's role was critical in effectively delivering the mentoring program. This individual had extensive experience in health education and mentoring of children. The coordinator worked collaboratively with the program evaluator to develop the program and set program expectations. Meetings between the coordinator and evaluator were conducted to ensure consistency among progran leadership, delivery, and desired outcomes. The coordinator provided ongoing contact and support with parents by email messages, telephone conversations, and face-to-face meetings. This individual also served as a liaison between parents and school, parents and mentor, mentors and students, and the school and the evaluator.

\section{Table 1}

Impact of Healthy Kids Mentoring Program

on Self-Esteem, School, Peer, and Family Connectedness

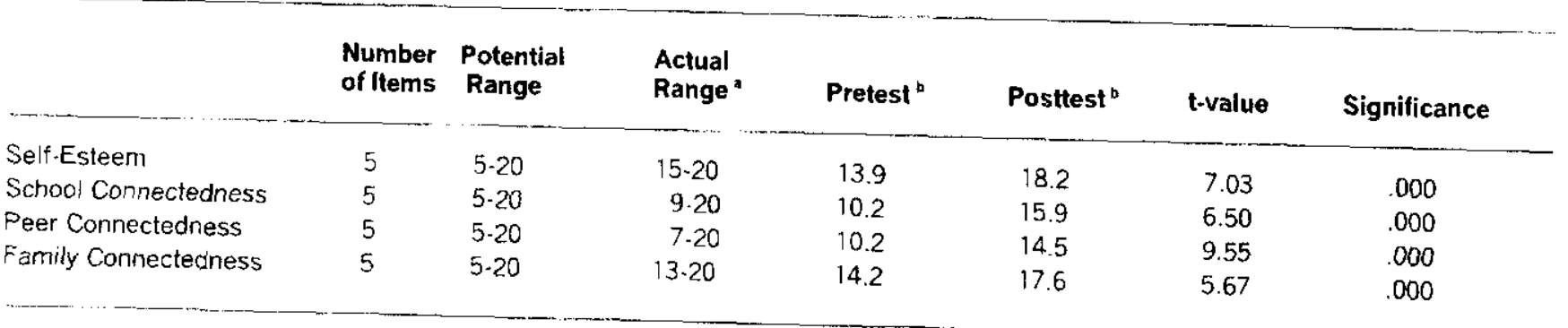

$N=28$ students

- Actual ranges based on posttest scores

- Mean scores based on a four-point Likert-type scale ( $1=$ strongly disagree, $2=$ disagree, $3=$ agree, $4=$ strongly agree) 


\section{Instrument}

A four page, 55-item survey instrument was developed based on a review of the literature to measure students' overall self-esteem: school, peer, and family connectedness; and involvement in unhealthy behavior. Four subscales (self $\sim$ esteem, school connectedness, peer connectedness, family connectedness) were assessed using a modified version of the Hare Abbreviated Self-Esteem scale. ${ }^{26}$ Each subscale consisted of five self-esteem items and required students to respond by using a four-point Likert-type scale ( 1 = strongly disagree, 2 = disagree, $3=$ agree, $4=$ strongly agree).

Students' involvement in unhealthy behavior was assessed by 35 items that addressed a variety of health behaviors including nutrition $(n=9)$; physical activity $(\mathrm{n}=$ $2)$; hygiene $(n=3)$; safety $(n=5)$; violence $(n=5)$; depression $(n=2)$; alcohol, tobacco, marijuana, and inhalant use $(n=6)$; and communication with adult role models $(n=3)$. Health behavior items were formatted similarly to the Youth Risk Behavior Survey." Nutrition, physical activity, hygiene, and safety items were not used for student entry into the program but to gain overall information about student behavior for usc later by the school.

Violence, depression, and substance use items were used as criteria for program admission. Students were required to indicate their recent involvement in weapon carrying, weapon carrying on school grounds, bullying, being bullied, physical fighting, and depression by circling the appropriate number of days they engaged in such behavior the past 30 days. Substance use items measured lifetime use of alcohol, tobacco, marijuana, and inhalants (yes or no) and recent use (use in the past 30 days). Students also were required to state how frequently they talked to a parent/legal guardian, adult at school, and/or friend when they had a problem by using a five-point Likert-type scale ( 1 = never, 5 = always).

Stability reliability (test-retest reliability) of the instrument was assessed by distributing the survey to a sample of fourth-grade students $(\mathrm{N}=32$ ) on two occasions one week apart, yielding Pearson $r$ correlation coefficients of .70 for health behaviors, .85 for self-esteem, .81 for school connectedness, .73 for peer connectedness, and .73 for family connectedness. Internal reliability of the instrument was assessed by computing Cronbach alphas for each of the subscales: .66 (health behaviors), .81 (self-esteem), .80 (school connectedness), .72 (peer connectedness), and .76 (family connectedness).

\section{Student Admission into Program}

In October 1999, the survey was distributed to all fourthgrade students $(\mathrm{N}=283)$ at a midwestern suburban public school. Recent letter grades also were obtained for each student. Data then were analyzed to identify students in need and eligible for the mentoring program. Students in need met one of the following conditions: 1) had selfesteem scores at least one standard deviation below the group mean, 2) had engaged in two or more risky health behaviors, 3) had been sad or depressed for two consecutive weeks in the past month, 4) had abused alcohol, 1obacco, or other drugs in the past 30 days, 5) had failed two or more classes in the first academic quarter of 1999. Based on these criteria, 32 students were selected for the program. These students met with the school counselor to validate their survey responses. All 32 students reported honestly answering the survey items. Parents of the students then were contacted to gain consent for student admission into the mentoring program. Parents of four students declined to grant consent. The remaining 28 students ( 11 girls and 17 boys) received parental consent and were admitted into the program.

\section{Evaluation Procedures}

All fourth-grade students completed the 55-item survey instrument in October 1999 in their homerooms. The survey items and instructions were read verbatim to students to increase internal validity of the evaluation by

Table 2

Comparison Between Mentoring Group and Control Group on Self-Esteem Levels, and School, Peer, and Family Connectedness

\begin{tabular}{|c|c|c|c|c|}
\hline & Pretest & Posttest & F-value & Significance \\
\hline \multicolumn{5}{|l|}{ Self-Esteem } \\
\hline Mentor Group & 13.9 & 18.2 & 0.48 & NS \\
\hline Control Group & 18.1 & 18.5 & & \\
\hline \multicolumn{5}{|c|}{ School Connectedness } \\
\hline Mentor Group & 10.2 & 15.9 & 33.45 & .000 \\
\hline Control Group & 12.3 & 12.2 & & \\
\hline \multicolumn{5}{|c|}{ Peer Connectedness } \\
\hline Mentor Group & 10.2 & 14.5 & 0.85 & NS \\
\hline Control Group & 13.6 & 13.9 & & \\
\hline \multicolumn{5}{|c|}{ Family Connectedness } \\
\hline Mentor Group & 14.2 & 17.6 & 39.53 & .000 \\
\hline Control Group & 14.0 & 14.2 & & \\
\hline
\end{tabular}

$N=28$ students

Mean scores based on a four -point Likert-type scale $(1=$ strongly disagree, $2=$ disagree, $3=$ agree, $4=$ strongly agree) 
minimizing potential difficulties from student reading abilities. Students completed the survey as the proctor read each question and possible scale responses. Students meeting these criteria, and having parental consent, were admitted into the program.

The program began the first week of January 2000 and ended the last week of May 2000. In June 2000, all fourthgrade students $(N=283$ ) completed another survey (the same instrument as the pretest) according to the same pretest administration procedures. An end-of-the-year celebration banquet was held at the school for students and parents in the program. Qualitative data regarding program effectiveness was obtained from parents and students at the banquet (parents of two students did not attend) and by post-program telephone conversations conducted by the program coordinator.

\section{Data Analysis}

Descriptive statistics, including frequencies, means, and standard deviations, were used to examine demographic and background characteristics of respondents. Paired sample t-tests were conducted to assess program impact on mentored students' self-esteem, connectedness, and engagement in risky health behavior. Analyses of variance (ANOVAs) examined parametric subscale data. All data analyses were performed by the Statistical Software
Package for the Social Sciences (SPSS). Alpha level of significance was set at .05 to reduce the likelihood of committing a Type I error.

\section{RESULTS}

\section{Impact of Program on Self-Esteem and Connectedness Scores}

Paired sample t-tests were conducted to assess program impact on mentored students' self-esteem and connectedness scores from pretest to posttest. Results indicated students' overall self-esteem, school connectedness, peer connectedness, and family connectedness were significantly higher at posttest than at pretest (Table 1). A more specific item-by-item display of pretest-posttest scores for mentored students is presented in Table 2.

To assess potential differences between the experimental group (mentored students) and the control group (nonmentored students) a series of F-tests was conducted. Compared to nonmentored students, mentored students achieved significantly higher school connectedness and family connectedness scores at posttest (Table 3). While mentored students improved statistically from pretest to posttest in their overall self-esteem and peer connectedness scores, posttest scores in these two areas did not differ significantly from nonmentored students' scores.

Table 3

Mentoring Students' Self-Esteem, Peer, School, and Family Connectedness Scores

\begin{tabular}{|c|c|c|}
\hline Subscale Item & $\begin{array}{l}\text { Pretest } \\
\text { M (SD) }\end{array}$ & $\begin{array}{c}\text { Posttest } \\
\text { M (SD) }\end{array}$ \\
\hline \multicolumn{3}{|l|}{ Self-Esteem } \\
\hline I like myself & $2.80(.96)$ & $3.70(.47)$ \\
\hline I feel there are many good things about me. & $3.13(.94)$ & $3.67(.48)$ \\
\hline 1 feel proud of myself. & $2.83(.79)$ & $3.73(.45)$ \\
\hline I feel confident. & $2.87(.97)$ & $3.63(.49)$ \\
\hline \multicolumn{3}{|l|}{ I like the way I am. } \\
\hline \multicolumn{3}{|l|}{ Peer Connectedness } \\
\hline I have as many friends as others my age. & $2.37(1.1)$ & $2.63(1.1)$ \\
\hline I am as popular as others my age. & $3.10(.76)$ & $3.47(.94)$ \\
\hline Other my age think I am fun to be with. & $2.63(1.3)$ & $3.10(.99)$ \\
\hline Other my age wish there were like me. & $1.97(1.1)$ & $1.90(.80)$ \\
\hline I am a person others turn to for help. & $1.57(.50)$ & $3.40(.72)$ \\
\hline \multicolumn{3}{|l|}{ School Connectedness } \\
\hline My teachers are fair with what they expect from me. & $2.96(1.1)$ & $3.50(.63)$ \\
\hline am usually proud of my report card. & $2.60(1.3)$ & $3.07(1.0)$ \\
\hline School is as hard for me as it is for most others. & $2.82(.92)$ & $3.23(.94)$ \\
\hline My teachers are happy with the kind of work I do. & $2.40(1.0)$ & $3.27(.58)$ \\
\hline Most of my teachers understand me. & $2.50(.90)$ & $2.83(1.2)$ \\
\hline \multicolumn{3}{|l|}{ Family Connectedness } \\
\hline My parents are proud of the kind of person 1 am. & $3.73(.64)$ & $3.80(.55)$ \\
\hline My family pays attention to me at home. & $3.00(.85)$ & $3.40(.77)$ \\
\hline My parents try to understand me. & $2.97(1.1)$ & $3.67(.61)$ \\
\hline I am an important person to my family. & $3.50(.82)$ & $3.44(.94)$ \\
\hline I feel wanted at home & $2.17(1.3)$ & $3.27(.83)$ \\
\hline
\end{tabular}

$N=28$ students

Mean scores based on a four-point Likert-type scale ( $1=$ strongly disagree, $2=$ disagree, $3=$ agree, $4=$ strongly agree) 


\section{Involvement in Health Behaviors}

Paired sample t-tests were conducted to assess program impact on mentored students' involvement in risky behavior. Health behaviors assessed included current involvement (within the past 30 days) in weapon carrying; fighting; bullying; depression; and alcohol, tobacco, marijuana, and inhalant use. At posttest, mentored students were significantly less likely to have bullied a peer in the past 30 days, $\mathrm{t}(27)=3.47, \mathrm{p}=.002$, to have physically fought with a peer in the past 30 days, $1(27)=3.48, \mathrm{p}=.000$, and to have felt depressed, $t(27)=2.97, p=.006$.

Students also indicated how safe they felt at school by using a four-point Likert-type scale $(1=$ extremely unsafe, $2=$ unsafe, $3=$ safe, $4=$ extremely safe). Mentored students were significantly more likely at posttest than at pretest to report feeling safer at school, $t(27)=3.47, p=$ .002 . Students also were asked to report how often they talk to their parent/guardian when they have a problem $(1=$ never, $2=$ rarely, $3=$ sometimes, $4=$ most of the time, $5=$ always). Data revealed that mentored students were significantly more likely at posttest than at pretest to report talking more frequently with their parent/guardian when they had a problem, $\mathrm{t}(27)=2.43, \mathrm{p}=.021$.

\section{Academic Achievement}

Academic grades for mentored students were evaluated before and after program implementation. One criterion for entry into the program was to have failed two or more classes in the first academic quarter of 1999. The mentoring program began in the middle of the second quarter (January 2000 ). Fourth-quarter grades were compared against firstquarter grades to assess potential program effects. Of 28 students in the program, 20 students $(71 \%)$ showed academic letter grade improvements from the first quarter. Of these 20 students, 18 improved their letter grades in reading. Seven students improved their grades in one to two subject areas, while 13 students improved their grades in three or more subject areas.

\section{DISCUSSION}

Research in school-based intervention indicates programs offering safe environments, encouragement and support, empowering activities, and specific guidelines for appropriate behavior contribute to increased self-esteem. Mentoring programs that successfully incorporate such aspects are associated with improved student attitude toward school, healthier behavior, and fewer absences, detentions, and suspensions. ${ }^{15.21 .18}$ School-based programs can enhance student self-esteem by focusing on academic achievement, and school, peer, and family connectedness. ${ }^{17,1 x}$

This exploratory study was conducted to assess the effectiveness of the Healthy Kids Mentoring Program. The following limitations affect evaluation of the program. First, the program was delivered to elementary students at one suburban school district in southwestern Ohio. Results may not generalize to other grades, schools, or programs. Fulure years of the program will focus on fourth- and fifthgrade students. Second, the control group may have included randomly assigned students who were part of the mentoring program after follow-up data collection took place. However, a "delayed" control group as such still would lend itself to limitations of equivalence, because the control group would not completely parallel the experimental group. Third, the control group may have been obtained through random-assignment of students from a matched school. However, concerns of school-by-school comparisons restricted this type of sampling method. Finally, outcomes from this study may result from potential threats such as testing, maturation, and history. Thus, exercise caution when attempting to generalize results from this study.

The Healthy Kids Mentoring Program produced significant increases in student self-esteem, academic achievement, and positive school, peer, and family connectedness. The program placed emphasis on building a relationship between student and mentor, employing various icebreakers and self-esteem enhancement activities. Previous mentoring programs often relied solely on the nature of the relationship to increase self-esteem. ${ }^{21}$ Healthy Kids is a unique mentoring program that specifically addressed these two components on a weekly basis.

Results from the Healthy Kids Mentoring Program revealed that the program significantly affected students sense of school and peer connections. The National Longitudinal Study of Adolescent Health cited school connectedness as the leading protective factor against violence, suicide, depression, substance abuse, early sexual involvement, and teen pregnancy." Positive school connections prove critical to student engagement in healthy behavior. As noted, time and emphasis were devoted to building positive school and peer connections among mentored students. Mentors received an arsenal of icebreaker and relationship-building activities to use with students. Offering mentoring sessions only on school grounds may help students to direct positive feelings about the program toward the school, thus improving their overall school attitudes. ${ }^{15}$ Continued support, care, and encouragement from adults also helps produce more favorable attitudes. ${ }^{29}$

Interestingly, while the Healthy Kids program did not possess a specific component facilitating peer relationships, mentored students reported higher levels of peer connectedness after the program. Positive peer relationships are important to the development and continued maintenance of social, emotional, and mental well-being." Within the goal-setting component of the Healthy Kids program, a common long-term goal was to "make a lot of friends." To accomplish this long-term goal, mentors worked with students on communication skills, characteristics of quality friendships, and what it means to be a "good friend." In addition, short-term goals such as "complimenting at least one peer today," "thanking one peer each day for his or her help," and "helping a peer to accomplish a task" may have contributed to improved peer connectedness at the end of the year.

Mentored students' sense of family connectedness improved after program completion, perhaps due to a carryover effect from students spending four months conversing and developing a positive relationship with an adult mentor. In addition, mentors encouraged students to talk with their parents about the program and about any problems they were experiencing. The need to regularly communicate with parents was a message continually delivered to students. Positive parental involvement represents an essential ingredient to healthy child growth and development ${ }^{34, i t}$ 
and, therefore, should become part of any mentoring program. Posttest data from this study revealed mentored scudents as significantly more likely at posttest than at pretest to report talking more frequently with their parent/guardian when they had a problem.

The academic assistance component of the Healthy Kids Mentoring Program associated positively with significant gains in student achievement during the fourth quarter. Approximately $71 \%$ of students improved their grades. These effects most likely occurred due to academic assistance and attention to students' feelings of connectedness and overall self-esteem. Positive student connections with school and family are associated with improved academic achievement and school performance. ${ }^{32}$ Mentors in the program set high but attainable academic expectations with students, characteristics of authoritative teaching/parenting styles that enhance student learning and display of appropriate behavior. ${ }^{37}$ Improved self-esteem scores that occurred have been associated with improvements in reading and academic performance.

\section{CONCLUSIONS}

Based on findings from this study, the following recommendations are offered to individuals interested in developing effective school-based mentoring programs.

1) Obtain and maintain administrative support.

2) Devote resources toward creation of a mentor project coordinator. Advocate for a school health coordinator.

3) Develop a multidimensional mentoring program that includes such components as relationship building, selfcsteem enhancement. goal setting, and academic assistance.

4) Recruit mentors from the community around the school.

5) Provide ongoing training sessions for mentors, and remain available for ongoing technical assistance.

6) Obtain parental and community support.

7) Keep parents informed about program events and progress.

8) During the planning phase, contact a program evaluator to help determine students eligible for the program, and to plan pretest-posttest analyses.

\section{References}

I. Youngs BB. Self-esteem in the school: more than a feel-good movement. NASSP Bull. 1993;76:59-66.

2. Brooks RB. Self-esteem through the school years: its normal development and hazardous dectine. Pediat (Clin North Am. 1992;39:537-549.

3. Lawrence D. Improving self-esteem and reading. Educ Res. 1985:27:194-20).

4. Gurncy F. Self-estem enhancement in children: a review of the lindings. Edth Re's. 1987:29:1 30-136.

5. Torres R, Femandey F, Maceira D. Self-esteem and value of health a' correlates of adolescent health behavior. Adolescence. 1995:30(118):4013-412

6. Miller RL. Positive self-esteem and alcohol/drug related attitudes among school children. I Alc Drug Educ. 1988:33(3):26-31.

7. Hershberger SL, Pilkington NW. D Augelli AR. Predictors of suicide attempts among gay, lesbian, and bisexuat youth. I Adolesc Re's. 1997: 12:477-497.

8 . Kaplan HI, Sadock BJ. Pocket Handbook of Clinical Psychiatry. Baltimore, Md: Williams \& Wilkins; 1990.

9. Resnick MD. Bearman PS. Blum RW. et al. Protecting adolescents from harm: findings from the National Longitudinal Study on Adolescent Health. JAMA. 1997;278:823-832.

10. McDermott RJ, Sarvelat PD, Hoalt PN. Bajracharyat SM, Marty PJ, Emery EM. Multiple correlates of cigarette use among high school students. ISch Hialth 1992:63:146-150.
11. Hawkins JD, Catalano RF, Miller JY. Risk and protective factors for alcohol and other drug problems in adolescence and early adulthood: implications for substance abuse prevention. Psychol Bull. 1992;112: 64-105,

12. Cole RL, Slocumb EM. Factors influencing safer sexual behaviors in heterosexual late adolescent and young adult collegiate males. $J$ Nurs Sicholarship. 1995;27(3):217-223

13. Hawkins JD, Catalano RF. Broadening the vision of education: schools as health promoting environments. I Sch Health. 1990;60: $178-180$.

14. Simons-Morton BG. Crump AD. Haynie DL, Saylor KE. Studentschool bonding and adotescent problem behavior. Health Educ Res. 1999;14:99-107.

15. O'Donnell J, Michalak EA, Ames EB. Inner-city youths helping children: after school programs to promote bonding and reduce risk. Soc Work Educ: 1997;231-240.

16. Benard B. Fostering Resiliency in Kids: Protective Factors in the Family, Sihool, and Community. San Francisco, Calif: Far West Laboratory for Educational Research and Development; 1991. ERIC Document Reproduction Services No. ED 335781.

17. Galloway D, Gallenberger C. A school made great by caring for kids. High School J. 1999;7:28-33.

18. McBride CM, Curry SJ, Cheadle A, et al. School-level application of a social bonding model to adolescent risk-taking behavior. $I S C h$ Health. 1995;65:63-68.

19. de Anda D. A qualitative evaluation of a mentor program for atrisk youth: the participants" perspective. Child Adoles Soc Work $I$. $2001 ; 18: 97-116$.

20. Ryan CA. Mentoring for success: female university students and "at-risk" middles school girls. JOPERD. 2000;71(9):37-39.

21. O'Donnell J, Hawkins JD, Catalano RF, Abbott RD, Day LE. Preventing school failure, drug use, and delinquency among low-income children in long-term intervention in elementary schools. Am. Orthopsychiartry. 1995;65(1):87-99.

22. Bean R. The Four Conditions of Self-Esteem: A New Approach for Flementary and Middle Schools. Santat Cruz, Calif: ETR Associations: 1992

23. Cambourne B. The Whole Story: Natural Learning and Acquisition of Literary in the Classroom. Auckland, New Zealand: A.shton Scholastic Lid; 1988.

24. Pinnell G. Fountas I. A Coordinator's Guide to Help America Read: A Handhook for Volunteers. Portsmouth, NH: Heinemann; 1997.

25. Office of Educational Research and Improvement. Read with Me A Guide for Student Volunteers Starting Early Childhood Literacy Programs. Washington, DC: US Dept of Education: 1997.

26. Kelley RM, Denny G, Young M. Abbreviated hare self-esteem scale: internal consistency and faclor analysis. Am I Health Studies. 1997;13(4):18()-186.

27. Centers for Disease Control and Prevention. Youth risk behavior surveillance - United States, 1999. MMWR. 2000;49(No. SS-5).

28. Martinek T, Schilling T, Johnson D. Transferring personal and social responsibility of underserved youth to the classroom. Urban Rev. 2001:33(1):29-45.

29. Talmi A, Harter S. Pathw'ays to better outcomes: Special adults as sources of support for young adolescents. Paper presented at the biennial meetings of the Society for Research on Adolescence, San Diego. Calif, 1998

30. Gauze C. Bukowski WM, Aquan-Assee J, Sippola LK. Interactions between family environment and friendship and associations with selfperceived well-being during early adolescence. Child Dev. 1996;67:220)12216.

31. Peterson GW, Leigh GK. The family and social competence in adolescence. In: Gullota TP, Adams GR. Montermayor R, eds. Advances in Adslescent Development: Vol.3. Developing Social Competency in Adolescence. Newbury Park, Calif: Sage.

32. Masselam VS, Marcus RF. Stunkard CL. Parent-adolescent communication, lamily functioning, and school performance. Adolescence. 1990:25:725-737.

33. Baumrind D. Parental disciplinary patterns and social competence in children. Youth and Society, 1978:9:239-276. 
Copyright of Journal of School Health is the property of Blackwell Publishing Limited. The copyright in an individual article may be maintained by the author in certain cases. Content may not be copied or emailed to multiple sites or posted to a listserv without the copyright holder's express written permission. However, users may print, download, or email articles for individual use. 